\title{
PENGOLAHAN LIMBAH RUMAH TANGGA TERPADU MENJADI SUMBER ENERGI ALTERNATIF DI DESA GLAGAHARUM Mochamad Syahrul Gunawan ${ }^{1}$, Niken Ayu Aprilia ${ }^{2}$, Wanda Dwi Pebrianti ${ }^{3}$, M. Hasan Abdullah ${ }^{4}$ \\ ${ }^{1}$ Universitas Wijaya Putra Surabaya \\ ${ }^{2}$ Univeristas Wijaya Putra Surabaya \\ ${ }^{3}$ Universitas Wijaya Putra Surabaya \\ ${ }^{4}$ Universitas Wijaya Putra Surabaya
}

Mochamadsyahrulgunawan@gmail.com, Nikenayuaprilia0425@gmail.com, Wandadwif25@gmail.com, mhasanabdullah@uwp.ac.id

\begin{abstract}
Abstrak
Bertambahnya jumlah penduduk mengakibatkan jumlah sampah semakin meningkat. Desa Glagaharum mempunyai 20 RT dan 4 RW yang terletak di Kecamatan Porong Kabupaten Sidoarjo. Sebanyak 5 RT terdampak bencana lumpur Lapindo sehingga mengalami penyempitan lahan. Sampah dari warga dibuang di lahan kosong dan dibakar. Proses pembakaran tersebut tidak sempurna sehingga memicu terjadinya pencemaran lingkungan baik tanah, air maupun udara. Berdasarkan permasalahan tersebut dibutuhkan solusi untuk menanggulangi jumlah sampah. Diantaranya dengan mengolah sampah rumah tangga menjadi sumber energi alternatif dengan teknologi pyrolisis dan biogas. Solusi tersebut dapat diimplementasikan melalui program pemberdayaan masyarakat. Metode pemberdayaan masyarakat dilaksanakan secara luring sesuai protokol kesehatan. Tahapan dalam program meliputi, 1) FGD (Forum Group Discussion), 2) Sosialisasi pengenalan program, 3) Pretest \& postest, 4) Rancangan invensi teknologi, 5) Pelatihan dan 6) Evaluasi. Adapun hasil dari pemberdayaan masyarakat yaitu , 1) Terjadi perubahan pengetahuan masyarakat yang ditandai dengan adanya perubahan nilai pretest dan posttest, 2) Terjadi perubahan fisik pada masyarakat yang ditandai adanya unit pengolahan sampah terpadu serta komunitas sebagai pengelola dan penanggungjawab unit tersebut.
\end{abstract}

Kata Kunci : Sampah, biogas, pyrolysis, energi alternatif

\section{PENDAHULUAN}

Sampah adalah sisa dari aktivitas manusia yang sudah tidak tepakai dan harus dikelola dengan baik. Banyak kerugian yang dapat ditimbulkan jika sampah tidak dikelola dengan benar, diantaranya adalah banjir, pencemaran tanah, pencemaran udara dan lain sebagainya yang merusak lingkungan, Permasalahan ini sudah menjadi permasalahan bersama, dan mambutuhkan penanganan yang tepat agar tidak merubah lingkunagan (Yudhistirani et al.,
2016). Desa Glagaharum terletak di kecamatan Porong kabupaten Sidoarjo. Desa tersebut terbagi menjadi 3 dusun, yaitu dusun Mrisen, dusun Glagah dan dusun Kwaron. Desa Glagaharum terdiri dari 20 RT dan 4 RW dengan jumlah keseluruhan 1.492 Kepala Keluarga. Kecamatan Porong berdasarkan data badan pusat Statistik (BPS) pada tahun 2019, memiliki jumlah penduduk 106.594 jiwa dan setiap tahun mengalami kenaikan. Sehingga berdampak terhadap ketersediaan sanitasi berupa pengelolaan sampah. (BPS, 2019) 
Berdasarkan hasil wawancara yang dilakukan oleh tim Program Holistik Pemberdayaan dan Pembinaan Desa (PHP2D) kepada kepala desa Glagaharum, bahwa sebanyak 5 RT terkena dampak dari semburan lumpur Lapindo. Akibatnya desa tersebut mengalami kesempitan lahan. Masyarakat tidak mempunyai tempat untuk pembuangan sampah. Sehingga sampah tersebut di buang disembarang tempat.
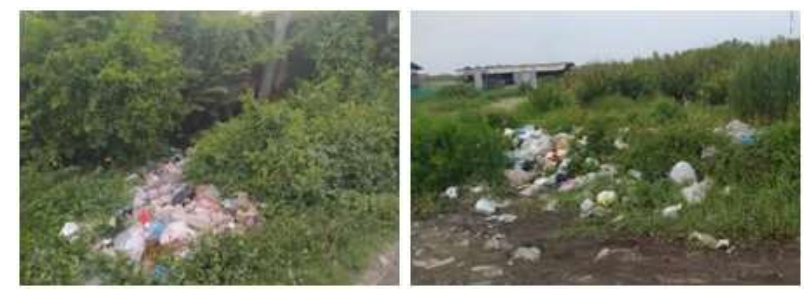

Gambar 1. Pembuangan sampah oleh warga

Warga juga melakukan pembakaran sampah di tepi jalan atau di dekat sungai. Proses pembakaran tersebut tidak sempurna sehingga memicu terjadinya pencemaran lingkungan baik tanah, air maupun udara.

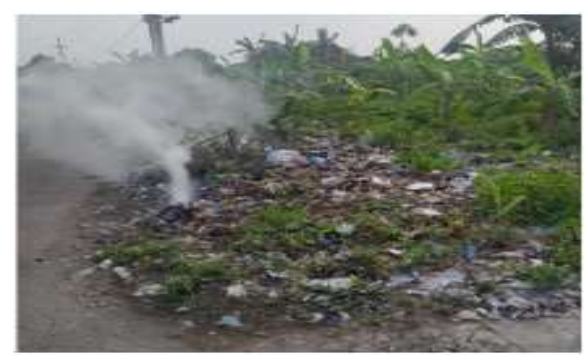

Gambar 2. Pembakaran sampah di ruang terbuka

Permasalahan yang di alami masyarakat adalah; 1) bagaimana memanfaatkan limbah rumah tangga menjadi energi alternatif guna mewujudkan desa mandiri energi di desa Glagaharum, 2) bagaimana merancang dan membuat teknologi tepat guna untuk mengolah sampah tersebut.

Berdasarkan permasalahan tersebut dibutuhkan solusi mengolah dan memanfaatkan sampah rumah tangga. Diantaranya dengan mengolah sampah rumah tangga menjadi sumber energi alternatif dengan teknologi pirolisis dan biogas (Wahyudi et al., 2018).

Tujuan dari program ini adalah tumbuhnya kesadaran dan terbentuknya kepedulian masyarakat terhadap lingkungan serta adanya tempat pegolahan sampah terpadu di desa Glagaharum. Pengolahan sampah terpadu tersebut diwujudkan melalui Program Holistik Pemberdayaan dan Pembinaan Desa dengan melakukan sosialisasi pemilahan dan pengolahan sampah untuk dijadikan Bahan Bakar Minyak (BBM) dan Biogas sebagai sumber energi listrik yang dapat dimanfaatkan di Desa Glagaharum. Produk lain yang dapat dihasilkan dari pengolahan sampah yaitu pupuk cair dan kompos.(Ashlihah, 2020)

\section{METODE}

Program pengabdian ini dilakukan dengan beberapa metode diantaranya; 1) FGD (Forum Group Discussion), 2) Sosialisasi dan pengenalan program, 3) Pre-test \& post-test, 4) Rancangan invensi teknologi, 5) Pelatihan, dan 6) Evaluasi program.

FGD diselenggarakan oleh Tim PHP2D bersama masyarakat atau mitra setempat terkait dengan program pengolahan sampah terpadu sebagai upaya untuk menanggulangi penumpukan sampah. FGD ini akan mampu mendorong ke arah tujuan yang lebih tepat dan bermanfaat bagi mitra.

Sosialisasi dan pengenalan program dilakukan supaya mitra (warga) dapat memahami maksud dan tujuan program. Sehingga program dapat diterima dan mendapat dukungan dari mitra.

Pre-test dan post-test dilakukan untuk mengetahui sejauh mana wawasan yang dimiliki mitra terkait dengan permasalahan sampah dan pengolahannya. Serta, untuk mengetahui pemahaman mitra setelah dilakukan pelatihan (Santoso et al., 2018).

Rancangan invensi teknologi yang digunakan dalam program mandiri energi yaitu mesin pirolisis untuk mengolah sampah anorganik dan mesin biogas untuk mengolah sampah organik. Teknologi ini akan menghasilkan BBM dan Biogas yang dimanfaatkan untuk menghidupkan Genset dan pembakaran Pirolisis. (Rachmawati \& Herumurti, 2015).

Pelatihan diberikan pada mitra agar mitra memahami jenis sampah serta mampu melakukan 
pemilahan sampah organik dan anorganik dengan benar dari rumah masing-masing sesuai dengan prinsip atau upaya 3R. Mitra juga diberikan pelatihan cara mengoperasikan dan merawat teknologi tepat guna yang sudah diberikan (Setiadi, 2015).

Evaluasi program dilaksanakan untuk mengetahui kekurangan atau kendala dalam pelaksanaan program. Kendala yang muncul akan dilakukan analisis dan rencana tindakan perbaikannya. Sehingga program dapat berjalan sesuai dengan tujuan yang telah direncanakan (Shofwan et al., 2019).

\section{HASIL DAN PEMBAHASAN}

\section{Pelaksanaan FGD (forum group discussion)}

Hasil dari pelaksanaan FGD yaitu permasalahan tentang sampah yang ada di desa Glagaharum, dengan hal itu tim PHP2D memberikan solusi tentang bagaimana pengolahan sampah dengan teknologi pirolisis dan biogas yang akan menghasilkan BBM setara solar yang akan dimanfaatkan untuk penerangan jalan.

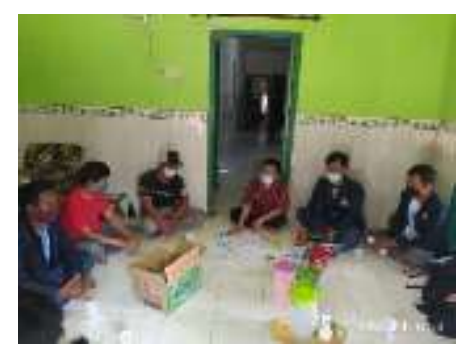

Gambar 3. Kegiatan FGD bersama Kepala Desa dan perangkatnya

\section{Sosialisasi dan pengenalan program}

Sosialisasi dan pengenalan program yang dilakukan pada warga, menunjukkan bahwa warga dapat menerima dan mempunyai antusias untuk melaksanakan program dari tim PHP2D. Kegiatan sosialisasi Tim PHP2D yang pertama pada hari Minggu tanggal 8 Agustus 2021 di kantor Balai Desa dan dihadiri oleh ibu-ibu PKK Desa Glagaharum.

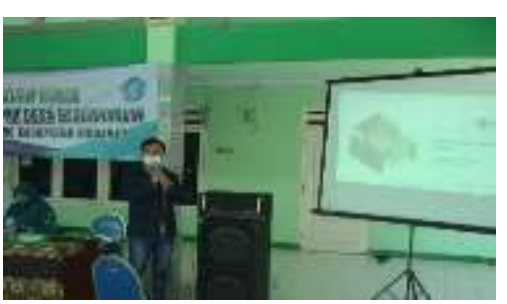

Gambar 4. Kegiatan sosialisasi bersama PKK

Pengenalan program ini bertujuan untuk mengenalkan pentingnya menjaga lingkungan sekitar dan juga cara pemilahan sampah dari rumah tangga. Sosialisasi kedua pada hari Minggu tanggal 29 Agustus 2021 yang dilakukan secara offline dengan mengambil 3 RT yaitu RT16, RT 11, dan RT 14 di desa Glagaharum, Kegiatan sosialisasi ini dilakukan secara door to door.
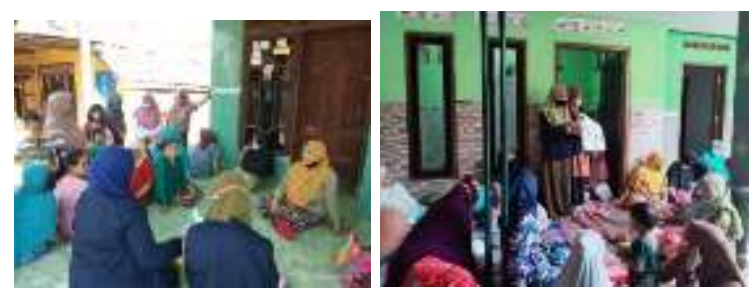

Gambar 5. Sosialisasi door to door

\section{Pelaksanaan Pretest dan posttes}

Pada hari Minggu tanggal 8 Agustus ibuibu PKK diberikan beberapa pertanyaan yang relevan dalam bentuk Pre-test, kepada ibu PKK dan warga diberikan edukasi dan sosialisasi tentang sampah organik dan organik. Kemudian diberikan beberapa pertanyaan dalam bentuk post-test untuk mengetahui tingkat pengetauan warga tentang sampah rumah tangga.

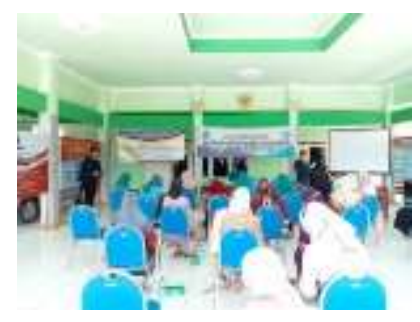

Gambar 6. Pelaksanaan Pretest dan Posttest 
Hasil dari 20 warga yang mengikuti pelaksanaan pretest dan posttes sebanyak $87 \%$ warga paham dan bersedia dalam mengelola sampah organic dan anorganik.

\section{Pembuatan Teknologi Tepat Guna (TTG)}

Teknologi tepat guna yang digunakan adalah pyrolysis dan biogas, Teknologi Pyrolysis nantinya akan digunakan untuk mengubah sampah anorganik (plastic) menjadi bahan bakar minyak. Sampah anorganik dibakar tanpa oksigen dengan suhu sekitar 400 derajat celcius kemudian menghasilkan uap yang dialirkan ke kondensor. Proses kondensasi akan terjadi 2 tahap penyulingan. Penyulingan pertama akan menghasilkan bahan bakar setara dengan solar. Uap yang lolos pada proses penyulingan pertama akan menuju proses penyulingan kedua yang akan menghasilkan bahan bakar setara bensin. Bahan bakar ini akan digunakan untuk menghidupkan guna menghasilkan energi listrik untuk penerangan fasilitas umum.

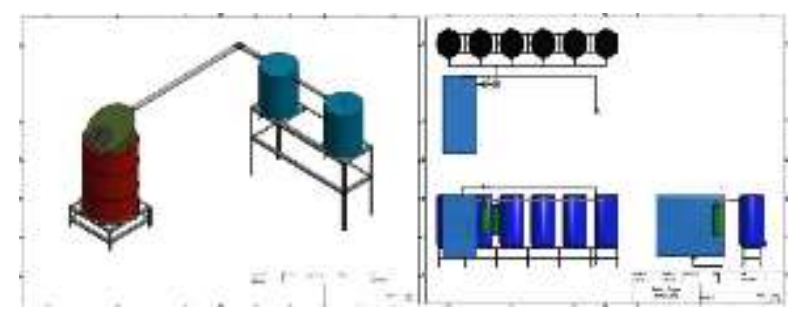

Gambar 7. Rancangan TTG pada program PHP2D

Sampah organik yang berasal dari rumah tangga akan diproses menggunakan reactor biogas yang terbuat dari drum plastic. Selain menghasilkan Biogas yang akan digunakan untuk memanaskan alat Pirolisis, reactor dapat menghasilkan residu berupa lumpur organic yang dapat digunakan sebagai pupuk. Gas yang dihasilkan juga dapat digunakan untuk menghidupkan mesin Genset berbahan bakar Hybrid (Minyak dan Gas). Tempat pengolahan sampah terpadu (TPST) ini dilengkapi dengan rumah produksi untuk penempatan alat dan tempat pemilahan sampah sementara.

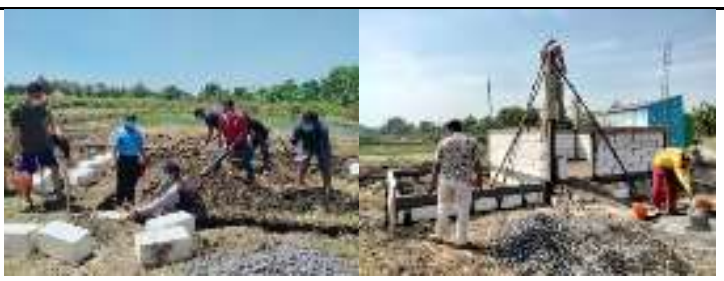

Gambar 8. TPST pada program PHP2D

\section{Pelatihan pemilahan dan pengolahan sampah}

Pelatihan yang dilakukan oleh tim PHP2D di ikuti oleh warga Desa Glagaharum dengan antusias. Hal ini terlihat dari tanyaknya peserta yang mengikuti pelatihan memilah sampah rumah tangga anorganik dan organik. Pelatihan juga diberikan kepada pengurus PKK dan perangkat desa sebagai kader lingkungan ditingkat RT.

Pemilahan sampah dari rumah dimaksudkan agar sampah yang akan dibuang ke tempat pengolahan sampah terpadu dapat langsung diproses sesuai dengan jenisnya. Sampah organic akan diproses menggunakan reactor biogas, sementara sampah anorganik dapat langsung dimasukkan kedalam mesin pirolisis.

Pelatihan diberikan pada mitra terkait dengan pengoperasian dan perawatan alat. Serta bagaimana memanfaatkan hasil dari proses konversi sampah menjadi energi dan pupuk. BBM hasil pirolisis perlu dilakukan pengendapan dan pemurnian sebelum digunakan untuk menghidupkan Genset. Biogas yang dihasilkan dari reactor ditampung dalam tempat khusus. Biogas tersebut dialirkan pada sebuah tabung yang sudah dilengkapi dengan filter. Filter ini bertujuan untuk menghilangkan gas impurities seperti $\mathrm{CO} 2$ dan $\mathrm{H} 2 \mathrm{~S}$. sehingga gas metan $\mathrm{CH} 4$ dapat digunakan secara optimal.

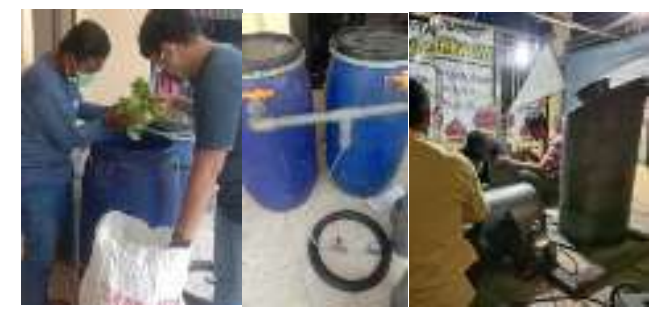

Gambar 9. Percobaan pada biogas dan pirolisis 


\section{Monitoring dan Evaluasi program}

Dari.

Tabel 1. Hasil monitoring dan evaluasi

\begin{tabular}{|c|c|c|}
\hline Program & Hasil & Tindakan \\
\hline FGD & $\begin{array}{l}\text { Teridentifikasinya } \\
\text { masalah di desa } \\
\text { Glagaharum yaitu } \\
\text { tentang sampah dan } \\
\text { air }\end{array}$ & $\begin{array}{l}\text { Pencarian solusi } \\
\text { dari permasalahan } \\
\text { sampah yang ada } \\
\text { di desa } \\
\text { menggunakan } \\
\text { teknologi tepat } \\
\text { guna }\end{array}$ \\
\hline Pre-post test & $\begin{array}{l}\text { Ada penigkatan } \\
\text { pemahan sebelumdan } \\
\text { setelah pelatihan }\end{array}$ & $\begin{array}{l}\text { Perlu } \\
\text { pendampingan } \\
\text { dalam pemilahan } \\
\text { sampah }\end{array}$ \\
\hline Sosialiasi & $\begin{array}{l}\text { Tumbuhnya } \\
\text { kesadaran } \\
\text { masyarakat tentang } \\
\text { pemilahan sampah, } \\
\text { guna di manfaatkan } \\
\text { menjadi barang yang } \\
\text { memiliki value lebih } \\
\text { dengan bank sampah } \\
\text { dan pengolahan } \\
\text { menjadi energi }\end{array}$ & $\begin{array}{l}\text { Membentuk } \\
\text { managemen } \\
\text { kelembagaan } \\
\text { yang unit } \\
\text { pengelolaan } \\
\text { sampah yang ada } \\
\text { di desa dan juga } \\
\text { kepengurusn bank } \\
\text { sampah }\end{array}$ \\
\hline $\begin{array}{c}\text { Pembuatan } \\
\text { TTG }\end{array}$ & $\begin{array}{l}\text { Adanya rumah } \\
\text { produksi serta reactor } \\
\text { pyrolysis dan reactor } \\
\text { biogas }\end{array}$ & $\begin{array}{l}\text { Pembuatan SOP } \\
\text { untuk } \\
\text { pengoperasian } \\
\text { dan maintenance } \\
\text { reactor pyrolysis } \\
\text { dan biogas }\end{array}$ \\
\hline Pelatihan & $\begin{array}{l}\text { Pelatihan di berikan } \\
\text { kepada mitra } \\
\text { Managemen bank } \\
\text { sampah dan juga } \\
\text { pengelola rumah } \\
\text { produksi, reactor } \\
\text { pyrolysis dan biogas }\end{array}$ & $\begin{array}{l}\text { Melatih } \\
\text { managemen bank } \\
\text { sampah dan juga } \\
\text { pengelola rumah } \\
\text { produksi, reactor } \\
\text { pyrolysis dan } \\
\text { biogas dengan } \\
\text { menggunakan } \\
\text { buku panduan } \\
\text { yang sudah di } \\
\text { buat }\end{array}$ \\
\hline
\end{tabular}

Berdasarkan tabel diatas dapat disimpulkan bahwa program pengabdian ini memberikan masyarakat wawasan tentang pemilahan dan pengelolaan sampah, Adanya perubahan fisik berupa adanya kegiatan bank sampah yang bertujuan untuk memberikan edukasi dan membiasakan warga untuk membiasakan memilah sampah dari rumah. Desa juga mempunyai TPSTyang terdiri dari rumah produksi, reactor pyrolysis dan biogas untuk mengelola sampah yang ada di desa.

\section{KESIMPULAN}

program pengabdian ini memberikan masyarakat wawasan tentang pemilahan dan pengelolaan sampah yang sebelumya masyarakat membuang sampah secara sembarangan. Dengan adanya program ini kesadaran masyarakat mulai tumbuh tentang menjaga lingkungan dan pengelolaan sampah. Perubahan fisik berupa adanya tempat pengolahan sampah terpadu (TPST) yang dapat mengolah sampah jenis organic dan anorganik. Mitra juga diberikan pendampingan terkait manajemen bank sampah dimana warga dapat membiasakan untuk memilah sampah mulai dari rumah masing-masing. Sampah yang tidak bernilai akan diproses di TPST untuk diolah menjadi bahan bakar minyak dan biogas. Produk lain yang dapat dimanfaatkan adalah pupuk yang dihasilkan dari sisa proses biogas. Pendampingan akan tetap dilakukan oleh Tim PHP2D sampai kegiatan selesai dan mitra dapat menjalankan program secara manidri.

\section{SARAN}

Keberlanjutan program perlu adanya support dari pihak pemerintahan desa juga Dinas Lingkungan Hidup (DLH) Kabupaten Sidoarjo serta pihak-pihak yang terkait.

\section{UCAPAN TERIMAKASIH}

Tim PHP2D UWP mengucapkan terima 
kasih kepada Pemerintahan desa Glagaharum, kelompok sasaran program dan juga seluruh warga desa Glagaharum yang telah menerima dan bersedia mengikuti pemberdayaan dan pelatihan oleh Tim PHP2D UWP. Terima kasih kami ucapkan kepada Universitas Wijaya Putra yang telah banyak mendukung dan memfasilitasi program PHP2D, serta kepada Direktorat Pembelajaran dan Kemahasiswaan Dikti yang telah membiayai kegiatan PHP2D tahun anggaran 2021.

\section{REFERENSI}

Ashlihah. (2020). Pelatihan Pemanfaatan Limbah Rumah Tangga Organik menjadi Pupuk Kompos. Jumat Pertanian ..., 1(1), 20182021.

http://ejournal.unwaha.ac.id/index.php/abdima sper/article/view/1054

BPS. (2019). Kecamatan Porong Dalam Angka 2019.

Rachmawati, Q., \& Herumurti, W. (2015). Pengolahan Sampah Secara Pitolisis dengan Variasi Rasio Komposisi Sampah dan Jenis Plastik. Jurnal Teknik ITS, 4(1), 27-29.

Santoso, A., Devi, M., \& Kurniawan, A. (2018). Peningkatan Pengetahuan Siswa Mengenai Jajanan Sehat Menggunakan Media Minicard. Preventia: The Indonesian Journal of Public
Health, 3(2), 153. https://doi.org/10.17977/um044v3i2p153-163

Setiadi, A. (2015). Studi pengelolaan sampah berbasis komunitas pada kawasan permukiman perkotaan di Yogyakarta. 3(April), 27-38.

Shofwan, I., Yusuf, A., Suryana, S., \& Widhanarto, G. P. (2019). Evaluasi Program "Model Logical Framework" untuk Pengelola Pusat Kegiatan Belajar. Jurnal Panjar, 1(1), 11-12.

Wahyudi, J., Prayitno, H. T., Astuti, A. D., Perencanaan, B., Daerah, P., \& Pati, K. (2018). Pemanfaatan limbah plastik sebagai bahan baku pembuatan bahan bakar alternatif the utilization of plastic waste as raw material for producing alternative fuel. XIV(1), 58-67. https://media.neliti.com/media/publications/27 1770-pemanfaatan-limbah-plastik-sebagaibahan-d2c72e6c.pdf

Yudhistirani, S. A., Syaufina, L., \& Mulatsih, S. (2016). Desain Sistem Pengelolaan Sampah Melalui Pemilahan Sampah Organik Dan Anorganik Berdasarkan Persepsi Ibu - Ibu Rumah Tangga. Jurnal Konversi, 4(2), 29. https://doi.org/10.24853/konversi.4.2.29-42 